
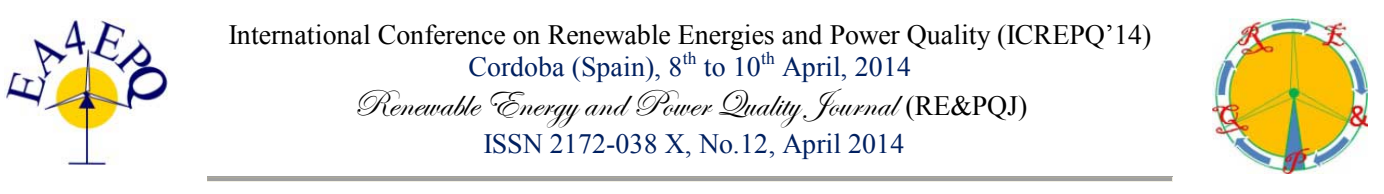

\title{
Sensitivity analysis of a High Gain DC/DC boost converter including parasitic parameters
}

\author{
F. Alonge ${ }^{1}$, M. Pucci $^{2}$, R. Rabbeni ${ }^{1}$ and G. Vitale ${ }^{2}$ \\ ${ }^{1}$ Università degli Studi di Palermo - Facoltà di Ingegneria \\ Dipartimento di Energia, Ingegneria dell'Informazione e Modelli Matematici - DEIM \\ Viale delle Scienze Palermo, Italy. \\ ${ }^{2}$ ISSIA-CNR (Insitute of Intelligent Systems for the Automation), Palermo, Italy \\ e-mail: pucci@pa.issia.cnr.it, vitale@pa.issia.cnr.it
}

\begin{abstract}
A high gain DC/DC boost converter is presented. This circuit is analysed with reference to the sensitivity analysis of the static gain transfer function including parasitic parameters. Results demonstrate that a low parasitic resistance of the input inductor gives a quasi-ideal behaviour in terms of efficiency and boosting but, on the other hand, it implies high variation of the static gain versus the duty cycle at its high. This kind of analysis is particular meaningful, since it has been demonstrated that the sensitivity of the HG (High Gain) boost DC-DC converter to the parasitic resistance of the input inductance is higher for lower values of the parasitic resistance.
\end{abstract}

\section{Key words}

DC/DC boost converter, sensitivity analysis.

\section{Introduction}

Efficiency improvement plays a key role in the choice and design of static power conversion systems. Among these, $\mathrm{DC} / \mathrm{DC}$ boost converters are frequently used in case of sources with low output voltage especially in energy conversion from renewables where they can perform the Maximum Power Point Tracking as well [1-5], and new topologies and devices have been studied to improve efficiency [6-7]. In addition, they guarantee a low ripple of the input current thanks to the presence of an inductor at the input; this last characteristic is important expecially when the power source is a Fuel Cell [8-13]. On the other hand, the parasitic resistance of the input inductor, dramatically affects the efficiency, for this reason the market proposes new realizations in which the quality of the inductor windings is improved to assure a parasitic resistance as lower as possible [14-15]. Thanks to these features, the range of the maximum duty cycle at which the converter can operate, is further increased.

In addition, new topologies with higher gain than the traditional boost converter have been devised so to avoid the necessity of cascade connection of more traditional boost (T-boost) converter [8, 16-18 ].
This paper presents an high gain DC/DC boost converter (HG-boost) whose ideal gain is equivalent to a two cascaded T-boost. A comparison of the sensitivity function of the gain for both the HG-boost and the Tboost converters is proposed in this paper. The aim of this study consists in verifying how a low parasitic resistance of the input inductance can influence the converter performance from the point of view of the control algorithm Finally the results calculated on a numerical example are discussed.

\section{Traditional Boost Converter}

The T-boost converter, shown in Fig 1, can be described by a state representation which describes the mean behaviour during the switching time $T_{s w}=1 / f_{s w}$ by the equations:

$$
\left\{\begin{array}{c}
\dot{x}=A x+B V_{I N} \\
y=C x
\end{array}\right.
$$

where $x=\left[\begin{array}{ll}i_{L} & v_{C}\end{array}\right]^{T}=\left[\begin{array}{ll}x_{1} & x_{2}\end{array}\right]^{T}$

$\left\{\begin{array}{l}A=A_{o n} D+A_{o f f}(1-D) \\ B=B_{o n} D+B_{o f f}(1-D) \\ C=C_{o n} D+C_{o f f}(1-D)\end{array}\right.$

and $D$ is the duty cycle of the power switch. The matrices $A, B$, and $C$ are given in appendix (with the symbols referred to Fig. 1).

The static gain, including parasitic elements is obtained as: 


$$
M_{T}=\frac{V_{O U T}}{V_{I N}}=-C A^{-1} B=\frac{1}{(1-D)+\frac{r_{L}}{R(1-D)}}
$$

It should be noted that, differently from the ideal case in which $r_{L}$ is neglected, the static gain is influenced by the ratio $r_{L} / R(1-D)$. This implies that, as the duty cycle increases, the ratio $r_{L} / R(1-D)$ becomes comparable to the quantity $(1-D)$ and the static gain exhibits a drop. On the other hand, the availability of an inductor with a low parasitic resistance improves the T-boost performance in terms of static gain and lessening of joule losses.

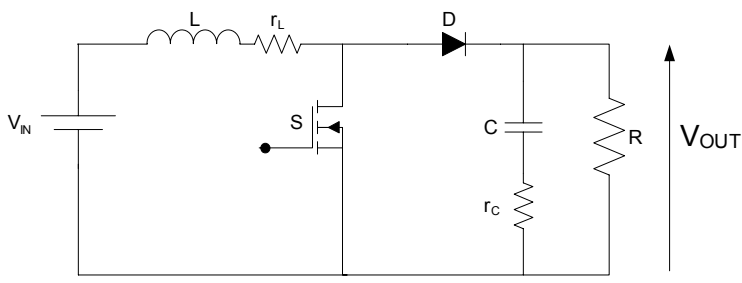

Fig. 1: Electric scheme of a the T-boost converter

\section{High Gain (HG) boost converter}

The HG-boost has been deeply examinated in [1], here only the fundamentals are given. The electric scheme is shown in Fig 2.

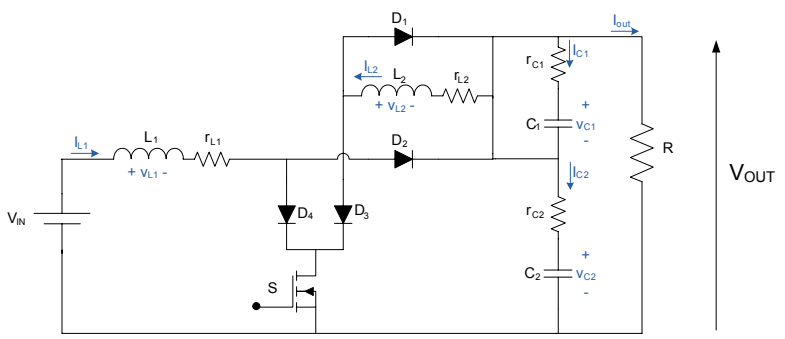

Fig. 2: Electric scheme of the HG-boost converter

Comparing the T-boost with the HG-boost it can be observed that the latter has two inductors, two output capacitors, four diodes but, like the T-boost, a unique power switch is required.

During $T_{O N}=D T_{s w}$ the power switch is in conduction state and the equivalent scheme is shown in Fig 3.

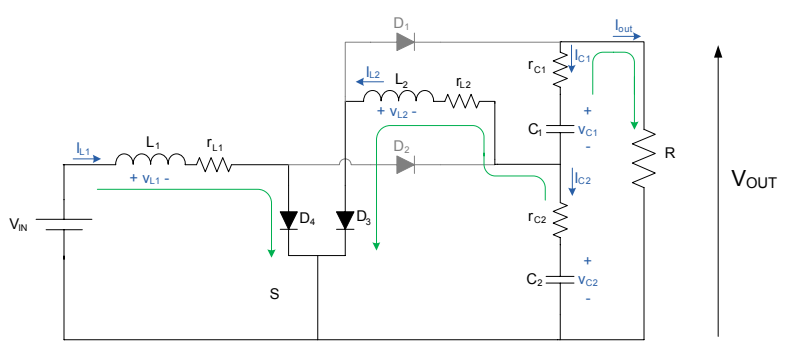

Fig. 3: Equivalent scheme of the HG-boost converter during $T_{\mathrm{ON}}$
The circuit is divided in two parts. A current flows from the supply charging the inductance $L_{l}$; the load is supplied by the capacitors and the inductance $L_{2}$ is charged by $C_{2}$.

During $T_{O F F}=(1-D) T_{s w}$ the power switch is in off state state and the equivalent scheme is shown in Fig 4 .

In this case, the inductors currents mantain the same direction supplying the load.

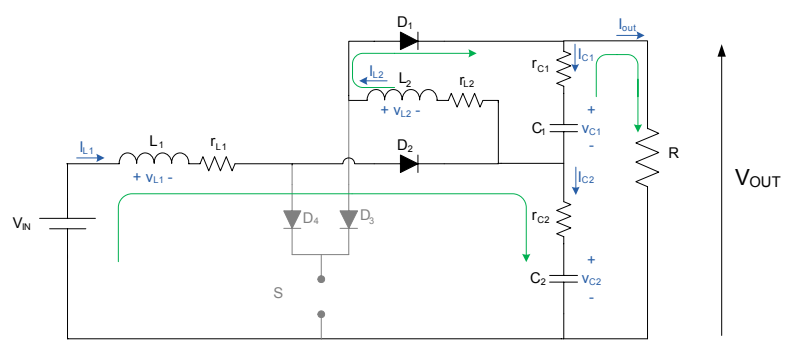

Fig. 4: Equivalent scheme of the HG-boost converter during $\mathrm{T}_{\mathrm{OFF}}$

Under the hypothesis of continuous conduction mode, by imposing that the mean voltage on the inductors is null, the following relationships are obtained:

$$
\begin{aligned}
& V_{C 2}=\frac{V_{I N}}{(1-D)} \\
& V_{C 1}=\frac{V_{C 2} D}{(1-D)}
\end{aligned}
$$

Now by taking into account that the output voltage is given by the sum of the voltage across the capacitors, the static gain in the ideal case is given by:

$$
\frac{V_{\text {OUT }}}{V_{I N}}=\frac{1}{(1-D)^{2}}
$$

It should be noted that the HG-boost exhibits a ideal gain equal to two cascade connected T-boost.

By applying the state space averaging technique, the matrices $\mathrm{A}, \mathrm{B}$, and $\mathrm{C}$ can be obtained and the gain in the real case is obtained as:

$$
M_{H G}=-C A^{-1} B=\frac{1}{(1-D)^{2}+\frac{r_{L 1}+r_{L 2}+r_{L 2} D^{2}}{R(1-D)^{2}}}
$$

Usually it is verified that $r_{L 2} D^{2}<<r_{L 2}<<r_{L 1}$, in this case the gain is influenced only by the ratio $r_{L} / R(1-D)^{2}$ that , differently from the T-boost, increases faster by increasing the duty cycle. For this reason, a drop on the voltage gain curve is expected for lower values of $D$ compared with the T-boost. Even in this case an input inductor with low values of parasitic resistance allows the HG-boost to be exploited in a wider range of $D$. 


\section{Sensitivity parameters analysis}

In general, for a DC/DC converter, a negligible variation of the static gain with the duty cycle and with the parasitic input inductor resistance should be desirable. This would make easier the control task to maintain the output voltage constant during the operation.

This attitude can be studied by calculating the static gain sensitivity as:

$$
\Delta M=\frac{\partial M}{\partial D} \Delta D+\frac{\partial M}{\partial r_{L}} \Delta r_{L}
$$

The sensitivity terms have been computed for both the Tboost and the HG-boot DC-DC converters.

\section{T-boost}

$$
\begin{aligned}
\frac{\partial M_{T}}{\partial D} & =\frac{\left[1-\frac{r_{L}}{R(1-D)^{2}}\right]}{(1-D)^{2}\left[1+\frac{r_{L}}{R(1-D)^{2}}\right]^{2}} \\
\frac{\partial M_{T}}{\partial r_{L}} & =\frac{-1}{R(1-D)^{3}\left[1+\frac{r_{L}}{R(1-D)^{2}}\right]^{2}}
\end{aligned}
$$

HG-boost

$$
\frac{\partial M_{H G}}{\partial D}=\frac{2\left(1-\frac{r_{L 1}}{R(1-D)^{4}}-\frac{2}{(1-D)^{4}}\right)}{(1-D)^{3}\left(1+\frac{r_{L 1}}{R(1-D)^{4}}+\frac{r_{L 2}}{R(1-D)^{2}}\right)^{2}}
$$

$$
\frac{\partial M_{H G}}{\partial r_{L 1}}=\frac{-1}{R(1-D)^{6}\left(1+\frac{r_{L 1}}{R(1-D)^{4}}+\frac{r_{L 2}}{R(1-D)^{2}}\right)^{2}}
$$

It should be noted that the higher $r_{L}$, the lower is the sensitivity. This results is in the opposite direction compared to the static gain curve. In other words an inductor with small parasitic resistance will require an accurate control algorithm expecially for high values of the duty cycle.

\section{Numerical examples}

A T-boost and a HG-boost converters have been designed to verify the influence of parasitic parameters in a practical case. In particular the HG-boost is designed with a rated power of $300 \mathrm{~W}$ and a supply given by a fuel cell (FC) with output voltage of $30 \mathrm{~V}$. The voltage at the output of the HG-boost is equal to a $200 \mathrm{~V}$, it corresponds to a rated load resistance equal to $175 \Omega$. Anyway, the internal resistance of the Fuel Cell (equal to about $0.3 \Omega$ ) has not been considered to perform the analysis only with reference to the converter. The T-boost utilizes the same inductor, capacitor and power switch. Both converters are analysed and compared so to obtain the characteristic curves for different values of the load and parasitic input inductor resistance versus the duty cycle. All values of the components are reported in Table I.

The curves representing the static gain of the T-boost versus the duty cycle with the input inductor as parameter is scketched in Fig. 5.

As expected, a low value of the parasitic resistance allows the converter to be used up to about $\mathrm{D}=0.8$ since the gain curve remains in the neighbourhoods of the ideal case.

The sensitivity curves are given in Figs 6,7 and 8 where the gain derivative respect to the duty cycle, the gain derivative respect to the duty cycle for different values of the parasitic input inductor resistance, the gain derivative respect to the parasitic input inductor resistance for different values of the parasitic input inductor resistance and of the load resistance are respectively reported.

Table I. - Values of the components adopted for the T-boost and HG-boost converters

\begin{tabular}{|c|c|c|c|}
\hline Component & symbol & T-boost & HG-boost \\
\hline IGBT & $\mathrm{T} 1$ & $\begin{array}{c}\text { IGBT N-Channel 30A - } \\
\text { 600V GW20NC60VD }\end{array}$ \\
\hline $\begin{array}{c}\text { Fast Power } \\
\text { Diode }\end{array}$ & $\mathrm{D} 1$ & \multicolumn{2}{|c|}{ STTH12R06 } \\
\hline $\begin{array}{c}\text { Fast Power } \\
\text { Diodes }\end{array}$ & D2,D3,D4 & - & $\begin{array}{c}\text { STTH12R0 } \\
6\end{array}$ \\
\hline $\begin{array}{c}\text { Input } \\
\text { inductor }\end{array}$ & $\mathrm{L} 1$ & $1.48 \mathrm{mH}, \mathrm{r}_{\mathrm{L} 1}=0.4 \Omega$ \\
\hline $\begin{array}{c}\text { Auxiliary } \\
\text { inductor }\end{array}$ & $\mathrm{L} 2$ & - & $\begin{array}{c}1.7 \mathrm{mH} \\
\mathrm{r}_{\mathrm{L} 2}=0.8 \Omega\end{array}$ \\
\hline $\begin{array}{c}\text { Output } \\
\text { capacitor }\end{array}$ & $\mathrm{C} 1$ & $100 \mathrm{uF}, \mathrm{ESR}=0.32 \Omega$ \\
\hline $\begin{array}{c}\text { Output } \\
\text { capacitor }\end{array}$ & $\mathrm{C} 2$ & - & $\begin{array}{c}100 \mathrm{uF}, \\
\mathrm{ESR}=0.32 \Omega\end{array}$ \\
\hline
\end{tabular}

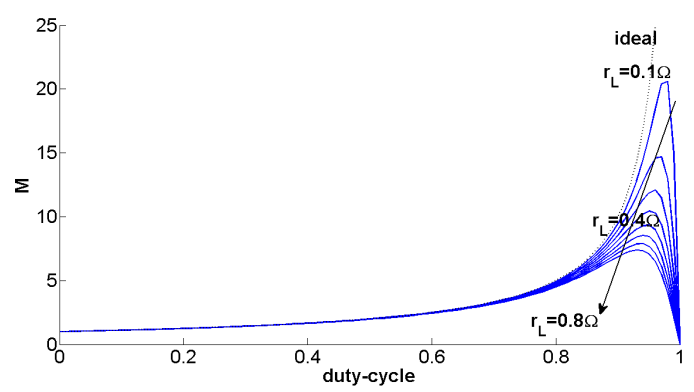

Fig. 5: Static gain of the T-boost versus the duty cycle 
All figures exhibit a very small value up to a duty cycle equal to 0.8 . It implies a relatively easy control of the converter. It should be borne in mind however that a very low value of the parasitic resistance would permit to work with high boost ratio but in this case the derivatives present higher variations.

These informations are summarized in the 3-dimensional plot of Figure 9 where it is more evident that when the load is far from the rated value for high boosting, the sensitivity is raised.

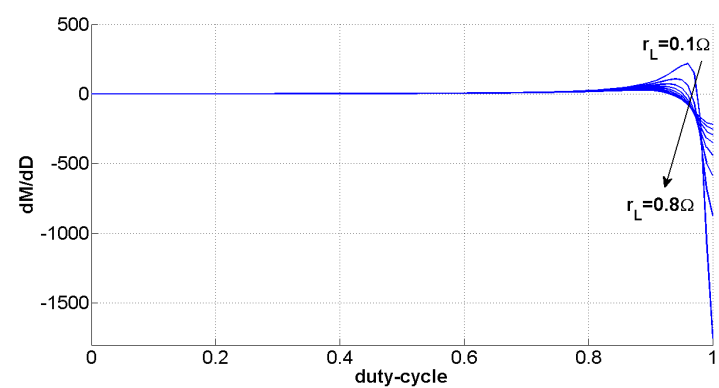

Fig. 6: Gain derivative respect to the duty cycle for different values of the parasitic input inductor resistance

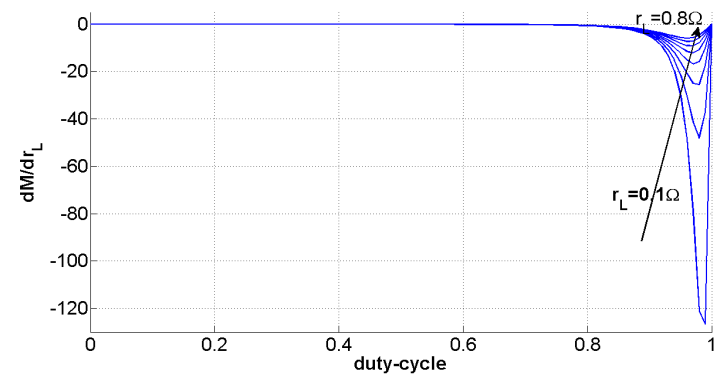

Fig. 7: Gain derivative respect to the parasitic input inductor resistance for different values of the parasitic input inductor resistance

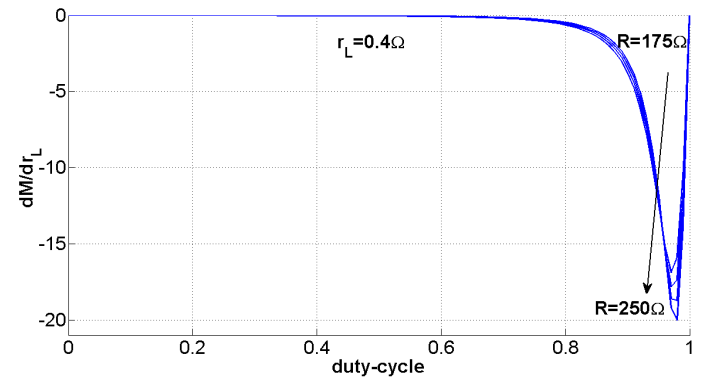

Fig. 8: Gain derivative derivative respect to the parasitic input inductor resistance for different values of the load resistance

The curve of the static gain of the HG-boost is shown in figure 10 where the parasitic input resistance is used as parameter. The shape of the curves is similar to the ones obtained for the T-boost, however the drop of the gain occurs for lower values of the duty cycle. This would suggest a possible control of the converter up to a values of the duty dycle near to about 0.7 (in the optimistic case of $r_{L}=0.1$ ), corresponding to gain equal to about 10 that on the contrary is dramatically reduced by a higher parasitic resistance values.

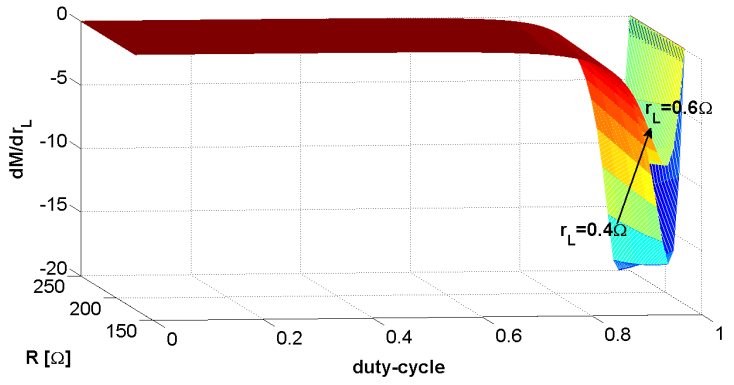

Fig. 9: 3-dimensional plot of the gain derivative respect to the parasitic input inductor resistance versus duty cycle and load values

Figures 11 and 12 show the derivative of the gain function versus the duty cycle adopting as parameter the parasitic resistance and the load resistance respectively.

The same considerations about the T-boost remain valid, however, it is more evident that a low value of the parasitic resistance of the input inductor induces high variation starting from $\mathrm{D}=0.6$. As the influence of the load value the operation in the neighboroud of the rated load is subjected to lower value of the sensitivity.

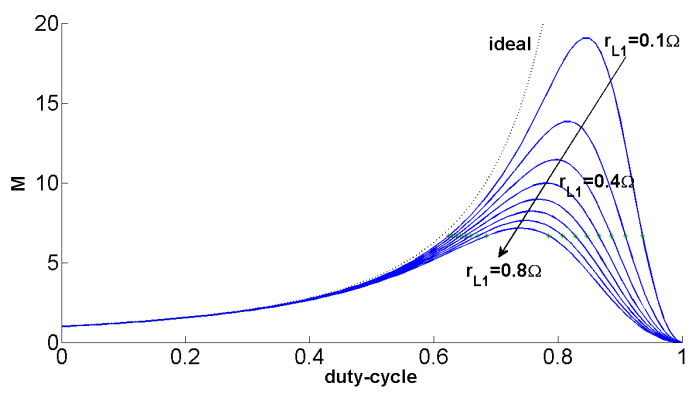

Fig. 10: Static gain of the HG-boost versus the duty cycle

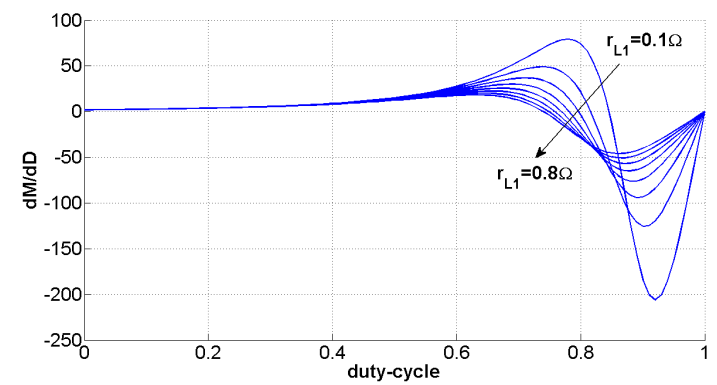

Fig. 11: Gain derivative respect to the duty cycle for different values of the parasitic input inductor resistance

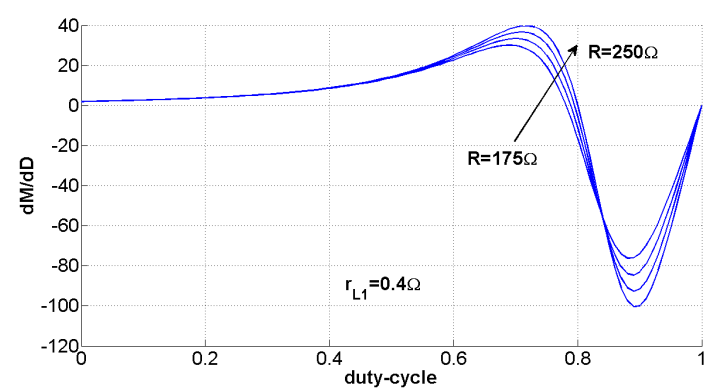

Fig. 12: Gain derivative respect to the duty cycle for different values of load resistance 


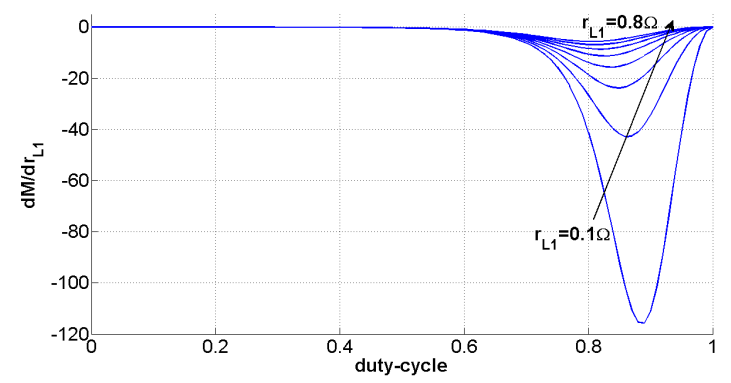

Fig. 13: Gain derivative respect to the parasitic input inductor resistance for different values of the parasitic input inductor resistance

Finally the derivative of the gain respect to the parasitic resistance, shown respectively in figure 14 assuming the parasitic resistance and in figure 15 assuming the load resistance as paramenter, assess the considerations that a low parasitic resistance makes more difficult the control task. In addition, since the parasitic resistance varies with the temperature duringthe operation, the control algorithm must be robust to face up with these variations. The 3-D plot of figure 15 gives a visual outline of the aforementioned considerations.

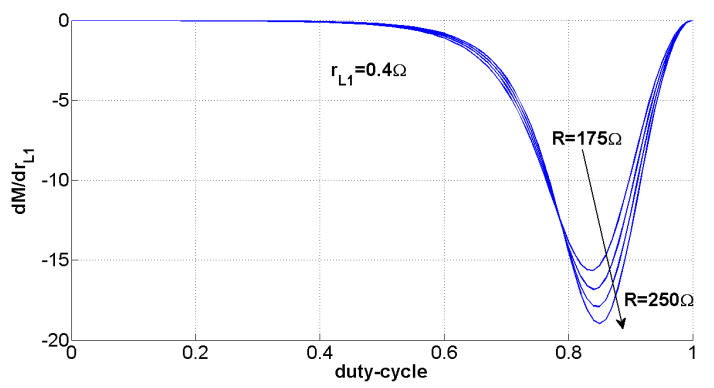

Fig. 14: Gain derivative respect to the parasitic input inductor resistance for different values of the load resistance

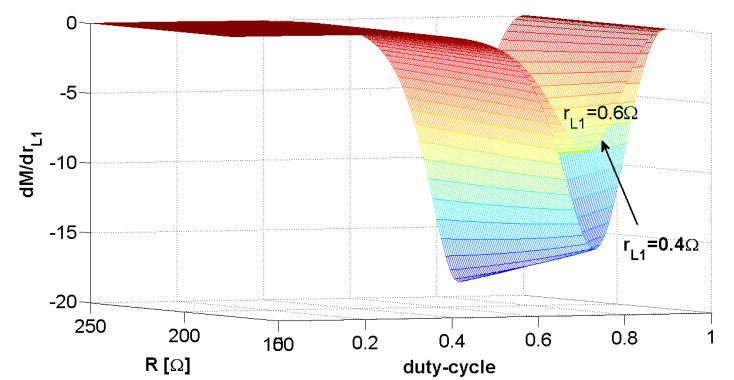

Fig. 15: 3-dimensional plot of the gain derivative respect to the parasitic input inductor resistance versus duty cycle and load values

\section{Experimental tests}

In order to highlight what above explained and to assess the theoretical analysis of the sensitivity on the $\mathrm{HG}$ converter, a series of tests have been performed. In these tests the load is step changed and the corresponding values of the output voltage and duty cycle are plotted. The converter is controlled in closed loop by a PID whose parameters are obtained by a classical frequency analysis method. The input voltage is maintained constant and equal to $30 \mathrm{~V}$, load is purely resistive and the reference voltage has been set to obtain an operation with the same value of the duty cycle for the three value of the parasitic input inductance resistance under test $(0.8 \Omega, 0.4 \Omega, 0.1 \Omega)$. Fig. 16 shows the output voltage versus time obtained with a load transition of 175-700-175 $\Omega$. It can be observed that the control system is able to control correctly the output voltage even with a step load variation.

It should be further noted that the curve obtained with a low parasitic resistance corresponds to the higher output voltage, on the other hand it is highly underdamped in correspondence of the load step increase. Moreover, the higher the parasitic resistance, the lower is the converter voltage caused by the reduction of the static gain. This is confirmed on figure 17 where the duty cycle versus time obtained with a load transition of $175-700-175 \Omega$ is shown. It can be noticed, in addition, that at steady state value, the same duty cycle are adopted by the controller. The tests shown in figures 18 and 19 are performed so to operate with the higher value of static gain sensitivity (worst case). For this reason both of the output voltage and corresponding duty cycles are different for the three values of the parasitic resistance. Even in this case, it can be observed that a low parasitic resistance is cause of oscillations during the load step variation.

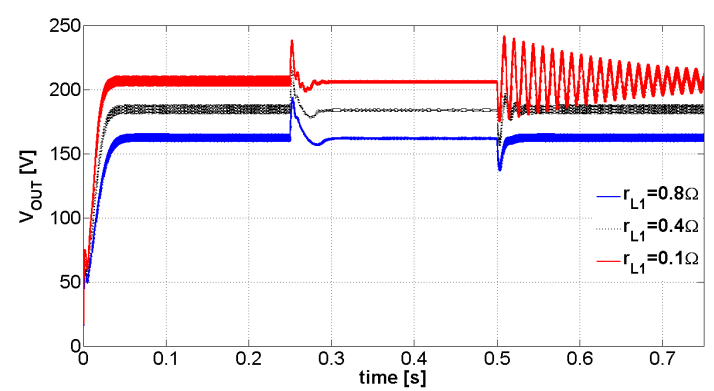

Fig. 16: Output voltage versus time obtained with a load transition of $175-700-175 \Omega$

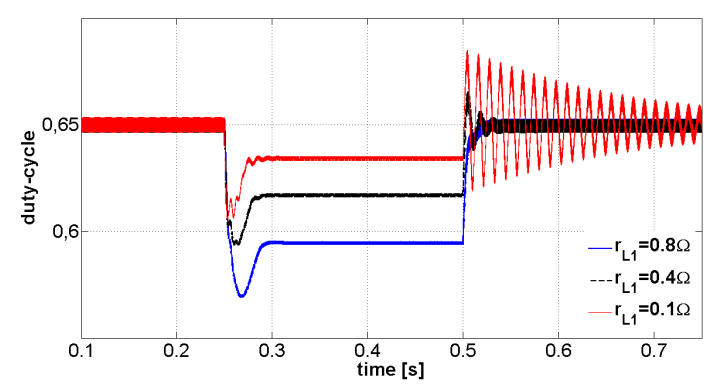

Fig. 17: Duty cycle versus time obtained with a load transition of $175-700-175 \Omega$. 


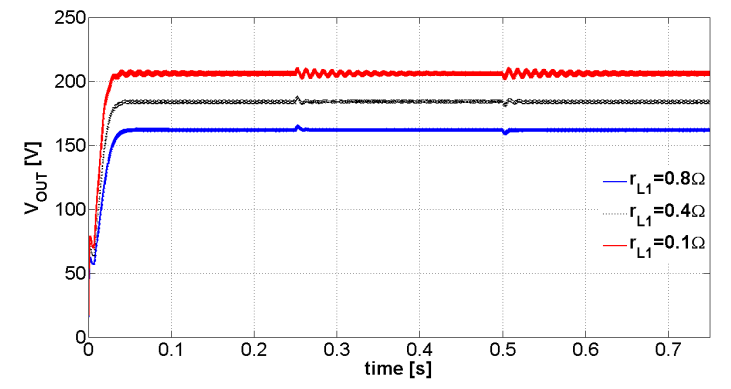

Fig. 18: Output voltage versus time obtained with a load transition of 400-500-400 $\Omega$.

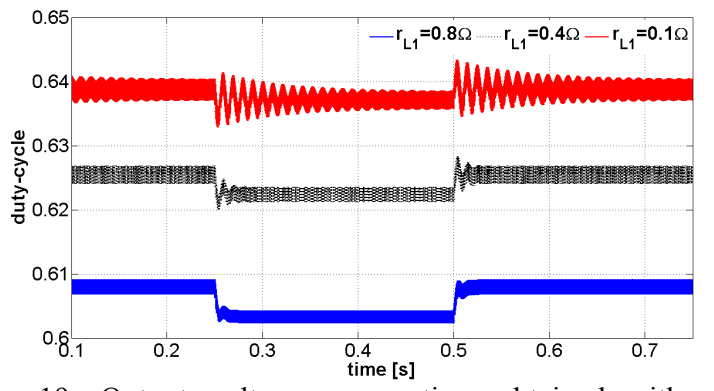

Fig. 19: Output voltage versus time obtained with a load transition of $400-500-400 \Omega$.

\section{Conclusions}

New topologies of high gain DC/DC boost converters give advantages in terms of voltage raising. The presence of an input inductance assures a low ripple of the input current. In order to increase the efficiency of these converters a low value of the parasitic resistance of the input inductance is desired. On the other hand, this dramatically increase the sensitivity of the static gain especially in the region of higher duty cycle, where the converter is required to be operated.

\section{Acknowledgement}

This paper has been funded by the following research projects: 1 . RITmare, Ricerca ITaliana per il mare (Italian Research for the sea) CUP:B91J11000740001; 2. TESEO, Tecnologie ad alta Efficienza per la Sostenibilità Energetica ed ambientale On-board (High efficiency technologies for on-board energy and environmental sustainability) CUP: B61C12000850005; 3. CNR per il Mezzogiorno (Advanced Technologies for Energy Efficiency and Sustainable Mobility) CUP: B51J10001290001.

\section{References}

[1] F. Blaabjerg, F. Iov, R. Teodorescu, Z. Chen, , "Power Electronics in Renewable Energy Systems", 12th International Conference on Power Electronics and Motion Control Conference, 2006. EPE-PEMC 2006 Page(s): 1 - 17.

[2] M. Luna, M. Pucci, G. Vitale, "Design of a Simple, Effective and Low Cost Micro-Wind Energy Conversion System", The Open Renewable Energy Journal (TOREJ), special issue on "Micro wind-power applications". 2011, 4, (Suppl 1-M6) 34-41 [3] Urtasun, P. Sanchis, L. Marroyo, "Adaptive Voltage Control of the DC/DC Boost Stage in PV Converters With Small Input
Capacitor", IEEE trans. on Power Electr. , Vol 28, Issue 11, 2013, pp. 5038- 5048

[4] M. C. Di Piazza, M. Pucci, A. Ragusa, G. Vitale "Fuzzified PI Voltage Control for Boost Converters in Multi-String PV Plants", 34th Annual Conference of the IEEE Industrial Electronics Society, IECON-2008. 10-13 November 2008.

[5] Geoffrey R. Walker, Member, IEEE, and Paul C. Sernia, "Cascaded DC-DC Converter Connection of Photovoltaic Modules", IEEE trans. on Power Electr., vol 19, no 4, July 2004.

[6] A. Shahin, J.-P. Martin, S. Pierfederici, "Optimal Efficiency Operation of Non-Isolated DC/DC Converter for High Voltage Ratio“, IECON 2013 - The 39th Annual Conference of the IEEE Industrial Electronics Society 10th 13th of November 2013, Vienna, Austria.

[7] R. Nielsen, L. S. Munk-Nielsen, F. Blaabjerg, “Efficiency and Cost Comparison of $\mathrm{Si}$ IGBT and SiC JFET Isolated DC/DC Converters", , IECON 2013 - The 39th Annual Conference of the IEEE Industrial Electronics Society 10th 13th of November 2013, Vienna, Austria.

[8] G. Marsala, M. Pucci, R. Rabbeni, G. Vitale, "Analysis and Design of a dc-dc Converter with High Boosting and Reduced Current Ripple for PEM FC", IEEE Vehicle Power and Propulsion Conference, VPP 2011, Chicago Il. USA, September 6-9.

[9] S. De Caro, A. Testa, D. Triolo, M. Cacciato, A. Consoli. "Low Input Current Ripple Converters for Fuel Cell Power Units", EPE 2005 Dresden.

[10] A. A. Fardoun, E. H. Ismail, A. J. Sabzali, M. A. Al-Saffar, "Bidirectional converter for high-efficiency fuel cell powertrain", Journal of Power Sources, 249 (2014) 470-482

[11] Jung-Min Kwon, Eung-Ho Kim, Bong-Hwan Kwon, Kwang-Hee Nam, " High-Efficiency Fuel Cell Power Conditioning System With Input Current Ripple Reduction", IEEE Trans. on Ind. Electr. Vol. 56, no 3, March 2009.

[12] Ching-Tsai Pan Shih-Kun Liang Ching-Ming Lai, "A Zero Input Current Ripple Boost Converter for Fuel Cell Applications by Using a Mirror Ripple Circuit", IEEE 6th International Power Electronics and Motion Control Conference, 2009. IPEMC '09.

[13] R. Bojoi, C. Pica, D. Roiu, A. Tenconi, "New DC-DC Converter with Reduced Low-Frequency Current Ripple for Fuel Cell in Single-Phase Distributed Generation", IEEE International Conference on Industrial Technology (ICIT), 2010 [14] H.Yang, C. Wang, P. Zheng, W. Wang, "On-chip high-Q inductor using wafer-level chip-scale package technology", IMPACT 2007, Int. Microsystems, Packaging, Assembly and Circuits Technology, 2007

[15] S. Wang, R. X. Wang, "Winding AC Resistance of Low Temperature Co-fired Ceramic Inductor", IEEE Electronics Letters, Vol. 47 , Issue: 16, Publication Year: 2011 , Page(s): $921-922$

[16] Z. Qun and F. C. Lee, "High-efficiency, high step-up DCDC converters", IEEE Trans. Power Electron., vol. 18, no. 1, pp. 65-73, Jan. 2003.

[17] C. Wang, Y. Kang, B. Lu, J. Sun, M. Xu, W. Dong, F. C. Lee, and W. C. Tipton, "A high power density, high efficiency front-end converter for capacitor charging application", in Proc. IEEE APEC, Mar. 2005, vol. 2, pp. 1258-1264.

[18] N. Vázquez, J. Leyva, I. Cervantes, L. Diaz, C. Hernández, "Analysis and Study of High DC/DC Boost Converters", IECON 2013 - The 39th Annual Conference of the IEEE Industrial Electronics Society 10th -13 th of November 2013, Vienna, Austria. 


\section{Appendix: state space representation matrices}

T-boost

$A=\left[\begin{array}{cc}-\frac{r_{L}}{L} D-\frac{r_{C} r_{L}+R\left(r_{C}+r_{L}\right)}{L\left(R+r_{C}\right)}(1-D) & -\frac{R(1-D)}{L\left(R+r_{C}\right)} \\ \frac{R(1-D)}{C\left(R+r_{C}\right)} & -\frac{1}{C\left(R+r_{C}\right)}\end{array}\right] \quad B=\left[\begin{array}{c}1 / L \\ 0\end{array}\right] \quad C=\left[\begin{array}{cc}\frac{R r_{C}(1-D)}{R+r_{C}} & \frac{R}{R+r_{C}}\end{array}\right]$

HG-boost

$A=\left[\begin{array}{cccc}-\frac{r_{L 1}\left(R+r_{C 1}+r_{C 2}\right)+r_{C 2}\left(R+r_{C 1}\right)(1-D)}{L_{1}\left(R+r_{C 1}+r_{C 2}\right)} & \frac{r_{C 1} r_{C 2}(1-D)}{L_{1}\left(R+r_{C 1}+r_{C 2}\right)} & \frac{r_{C 2}(1-D)}{L_{1}\left(R+r_{C 1}+r_{C 2}\right)} & -\frac{\left(R+r_{C 1}\right)(1-D)}{L_{1}\left(R+r_{C 1}+r_{C 2}\right)} \\ \frac{r_{C 1} r_{C 2}(1-D)}{L_{2}\left(R+r_{C 1}+r_{C 2}\right)} & -\frac{r_{L 2}\left(R+r_{C 1}+r_{C 2}\right)+R r_{C 2} D+r_{C 1} r_{C 2}+R r_{C 1}(1-D)}{L_{2}\left(R+r_{C 1}+r_{C 2}\right)} & -\frac{R(1-D)+r_{C 2}}{L_{2}\left(R+r_{C 1}+r_{C 2}\right)} & \frac{R D+r_{C 1}}{L_{2}\left(R+r_{C 1}+r_{C 2}\right)} \\ \frac{-r_{C 2}(1-D)}{C_{1}\left(R+r_{C 1}+r_{C 2}\right)} & \frac{R(1-D)+r_{C 2}}{C_{1}\left(R+r_{C 1}+r_{C 2}\right)} & \frac{-1}{C_{1}\left(R+r_{C 1}+r_{C 2}\right)} & \frac{-1}{C_{1}\left(R+r_{C 1}+r_{C 2}\right)} \\ \frac{\left(R+r_{C 1}\right)(1-D)}{C_{2}\left(R+r_{C 1}+r_{C 2}\right)} & -\frac{R D+r_{C 1}}{C_{2}\left(R+r_{C 1}+r_{C 2}\right)} & \frac{-1}{C_{1}\left(R+r_{C 1}+r_{C 2}\right)} & \frac{-1}{C_{1}\left(R+r_{C 1}+r_{C 2}\right)}\end{array}\right]$
$B=\left[\begin{array}{c}1 / 1 \\ L_{1} \\ 0 \\ 0 \\ 0\end{array}\right]$
$B=\left[\begin{array}{lllll}\frac{R r_{C 2}(1-D)}{R+r_{C 1}+r_{C 2}} & \frac{R r_{C 1}(1-D)-R r_{C 2} D}{R+r_{C 1}+r_{C 2}} & \frac{R}{R+r_{C 1}+r_{C 2}} & \frac{R}{R+r_{C 1}+r_{C 2}}\end{array}\right]$.

